\title{
"Un homenaje a los cirujanos, que ya no están, pero siguen estando..."
}

\section{"A tribute to surgeons, who are no longer here, but will stay in our memory forever..."}

Leopoldo M. Torres Contreras

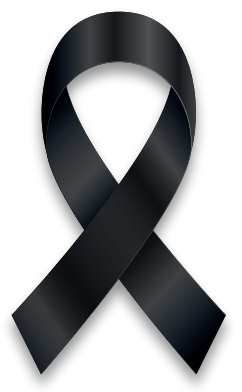

Los que amamos, nunca mueren, por eso en este día vamos a recordar con gusto y emoción a quienes nos formaron y a quienes fueron adiestrados en el servicio de Cirugía Pediátrica del Instituto Nacional de Pediatría, que desafortunadamente hoy ya no se encuentran con nosotros.

Nuestro Instituto nació en noviembre de 1970, hasta ahora han transcurrido 48 años, tiempo en el que en el servicio de Cirugía Pediátrica se han formado más de 160 cirujanos pediatras, que han representado un factor de cambio y de superación en hospitales de México y el extranjero.

La Asociación de Residentes de Cirugía Pediátrica se congrega cada año a partir de 1979, en reuniones que se han efectuado en México, Estados Unidos, Europa y el Caribe, en donde se revisan temas relevantes para el ejercicio de la Cirugía Pediátrica.

Ser agradecido es una cualidad y una obligación de todo ser humano que se precie de serlo, por eso hoy queremos decir ¡GRACIAS! a todos los que dejaron una huella en nuestra vida profesional y personal, por lo que considero justo recordar a:

Dr. Rigoberto Borrego Román (jefe del servicio de Oncología), excelente cirujano, gran ser humano, cortés con los residentes, querido y respetado por todos.

XL reunión de exresidentes de Cirugía del INP

Recibido: 27 de agosto 2018

Aceptado: 25 de febrero 2019

Correspondencia Leopoldo Torres-Contreras Imtorresc@yahoo.com

Este artículo debe citarse como Torres Contreras LM. "Un homenaje a los cirujanos, que ya no están, pero siguen estando...". Acta Pediatr Méx 2019;40(3):252-3. 
Dr. Lorenzo Pérez Fernández (jefe del servicio de Cirugía de Tórax), pilar de nuestra enseñanza, exigente, estricto, pero al mismo tiempo, justo. No solo enseñaba cirugía de tórax, sino también cómo tratar a los familiares y cómo planear todos los detalles de un procedimiento quirúrgico.

Dr. Lazar Moussali Flah (jefe del servicio de Urología), con un profundo deseo de enseñar, discreto, permitía operar a los residentes según sus merecimientos, con habilidad en el reparto de honorarios.

Dr. Humberto Castrejón Díez (adscrito al servicio de Cirugía Plástica y Reconstructiva), cirujano hábil, creativo, nunca de mal humor, lo que permitía un ambiente relajado y armonioso en el quirófano, respetuoso con los residentes.

Dr. Enrique Corona González (adscrito al servicio de Cirugía Cardiovascular), cirujano enérgico, con gran sentido de responsabilidad, interesado enormemente en sus pacientes.

Dr. Bibiano Alba García (primer jefe del servicio de Cirugía), magnífica persona, generoso siempre, todo el tiempo dispuesto a ayudar.

También recordamos a los siguientes compañeros que se formaron en el Instituto Nacional de Pediatría en diferentes periodos.

† Dr. Julián Díaz Ordaz (1972-74)

† Dr. José Rangel Aspe (1972-74)

† Dr. Rodolfo Monroy Laborde (1975-78)

+ Dr. Jalil Fallas Villegas (1975-78)
+ Dr. Andrés Cordero Olivares (1975-78)

+ Dr. José Rafael Reyes Zepeda (1976-79)

† Dr. Jorge Alberto González Nava (1977-80)

† Dr. Alejandro Andrade Lortia (1977-80)

† Dr. Francisco Sánchez Prieto (1978-81)

+ Dr. Carlos Calderón Elvir (1992-95)

Todos ellos han formado, forman y formarán parte de nuestra historia, compartieron con nosotros sueños, anhelos, desvelos, triunfos, fracasos, trabajo y esperanzas.

Para ellos nuestro respeto, admiración y los mejores recuerdos. Les rendimos recuerdos, les rendimos homenaje, con un arreglo de este sentido poema de David Harkins, Titulado:

\section{"Recuérdame"}

Podemos llorar porque se han ido, O podemos sonreír porque han vivido, Podemos cerrar los ojos y rezar para que vuelvan, O podemos abrirlos y ver todo lo que nos han dejado,

Nuestro corazón puede estar triste, porque no los vemos

O puede estar lleno de amor por lo que compartimos.

Podemos llorar, cerrar la mente, sentir el vacío y dar la espalda

O podemos hacer lo que a ellos les gustaría: sonreír, abrir los ojos y seguir hasta el final. 